\author{
R. Nano • B. Clissi - R. Melzi · G. Calori • P. Maffi • \\ B. Antonioli $\cdot$ S. Marzorati $\cdot$ L. Aldrighetti $\cdot$ M. Freschi $\cdot$ \\ T. Grochowiecki · C. Socci - A. Secchi • V. Di Carlo • \\ E. Bonifacio $\cdot$ F. Bertuzzi
}

\title{
Islet isolation for allotransplantation: variables associated with successful islet yield and graft function
}

Received: 29 July 2004 / Accepted: 4 January 2005 / Published online: 14 April 2005

(C) Springer-Verlag 2005

\begin{abstract}
Aims/hypothesis: Efficient islet isolation is an important prerequisite for successful clinical islet transplantation. Although progressively improved, islet yield and quality are, however, unpredictable and variable and require standardisation. Methods: Since 1989 we have processed 437 pancreases using the automated method. The donor characteristics, pancreas procurement, and digestion and purification procedures including a wide enzyme characterisation of these pancreases were analysed and correlated with islet yield and transplant outcome. Results: By univariate analysis, islet yield was significantly associated with donor age $(r=0.16 ; p=0.0009)$, BMI $(r=0.19 ; p=$
\end{abstract}

R. Nano · R. Melzi · P. Maffi · B. Antonioli · S. Marzorati ·

L. Aldrighetti · C. Socci · A. Secchi · V. Di Carlo ·

F. Bertuzzi $(\square)$

Medicine and Surgical Departments,

S. Raffaele Scientific Institute, Via Olgettina 60,

Milan, Italy

e-mail: bertuzzi.federico@hsr.it

Tel.: +39-02-26432961

Fax: +39-02-26432961

B. Clissi

Human Immunology Department, Dibit,

S. Raffaele Scientific Institute,

Milan, Italy

G. Calori

Statistics Unit, S. Raffaele Scientific Institute,

Milan, Italy

M. Freschi

Pathology Department,

S. Raffaele Scientific Institute,

Milan, Italy

T. Grochowiecki

Department of General, Vascular and Transplant Surgery,

Warsaw Medical School,

Banacha 1a,

02-097 Warszawa, Poland

E. Bonifacio

Immunology of Diabetes Unit,

San Raffaele Scientific Institute, via Olgettina 60,

20132 Milan, Italy
$0.0004)$, good pancreas condition $(p=0.0031)$ and weight $(r=0.15 ; p=0.0056)$, total collagenase activity $(r=0.22 ; p=$ $0.0001)$, adjusted collagenase activity $/ \mathrm{mg}(r=0.18 ; p=0.0002)$, collagenase activity/solution volume $(r=0.18 ; p=0.0002)$ and neutral protease activity/solution volume $(r=0.14 ; p=$ 0.0029 ). A statistically significant contribution to the variability of islet yield in a multivariate analysis performed on donor variables was found for donor BMI $(p=0.0008)$. In a multivariate analysis performed on pancreas variables a contribution was found for pancreas weight $(p=0.0064)$, and for a multivariate analysis performed on digestion variables we found a contribution for digestion time $(p=0.0048)$ and total collagenase activity $(p=0.0001)$. Twenty-four patients with type 1 diabetes received single islet preparations from single donors. In these patients, multivariate analyses showed that the reduction in insulin requirement was significantly associated with morphological aspects of islets $(p=$ $0.0010)$ and that 1 -month C-peptide values were associated with islet purity $(p=0.0071)$. Conclusions/interpretation: These data provide baseline donor, digestion and purification selection criteria for islet isolation using the automated method and indicate that the morphological aspect may be a clinically relevant measure of islets on which the decision for transplant can be based.

Keywords Collagenase - Insulin secretion - Islet isolation · Islet transplantation - Islet viability · Type 1 diabetes mellitus

Abbreviations IQR: interquartile range $\cdot$ NA: number of absolute islets $\cdot \mathrm{NE}$ : number of equivalent islets

\section{Introduction}

Islet transplantation in type 1 diabetic patients has recently been shown to correct the glucose metabolic homeostasis in all recipients $[1,2]$. Islet transplantation is therefore a therapeutic option for patients with brittle type 1 diabetes who have a sufficiently impaired quality of life to justify immunosuppression therapy [1]. 
Effective and cost-efficient islet transplant therapy requires consistent, successful isolation of islets from donor pancreases [3]. Although isolation has progressively improved, islet yield is highly variable. Poor donor selection, non-standardised procedures and the inconsistency of enzyme blends used for digestion are some of the parameters that contribute to this variability [4-8]. Analysis of enzyme blends and the islet isolation parameters that predict outcome have not been assessed.

The islet isolation center in Milan has processed over 500 pancreases and transplanted more than 100 islet preparations since 1989 . Here we have examined donor, digestion, and islet preparation characteristics in the pancreases and islet preparations, in order to identify the factors that are associated with high islet yield and improved beta cell function. The findings highlight some of the more relevant selection criteria for islet isolation in the setting of clinical islet transplantation.

\section{Subjects, materials and methods}

Between December 1989 and March 2003, 513 pancreas organs were obtained from heart-beating multi-organ donors through the Nord Italia Transplant Organization. Donor pancreas inclusion criteria for isolation were donor age between 17 and 70 years, and amylase values at least three times lower than the maximal normal values. The median cold ischaemia time was $6 \mathrm{~h}$ ranging from 1 to $17 \mathrm{~h}$. Two different solutions were used for organ preservation: University of Wisconsin (UW, ViaSpan; Bristol-Myers, Roma, Italy) and Celsior (IMTX-Sangstat, Milan, Italy). Upon receipt, pancreases were classified as being in good or bad condition defined on the basis of the gland integrity and on the quality of its perfusion. Of the 513 pancreases received, 76 were processed by non-conventional experimental methods; thus 437 were included in the analysis.

Islet isolation Islets were isolated using the automated method described by Ricordi [9]. Two types of enzymes were used: collagenase type $\mathrm{P}(1-3 \mathrm{mg} / \mathrm{ml})$ and liberase $(0.5-1.4 \mathrm{mg} / \mathrm{ml})$ (Roche, Indianapolis, IN, USA). Islets were purified by discontinuous gradient in syringes (density gradient: 1,108; 1,096; 1,037: Euroficoll, Sigma-Aldrich, Milan, Italy), or by continuous gradient with refrigerated COBE processor as previously described [10]. After isolation, islets were cultured at $22^{\circ} \mathrm{C}$ in a humidified atmosphere $\left(5 \% \mathrm{CO}_{2}\right)$, in M199 medium (Euroclone, Celbio, Milan, Italy) or CMRL (Mediatech, Cellgro, VA, USA) supplemented with $10 \% \mathrm{FCS}, 100 \mathrm{U} / \mathrm{ml}$ penicillin, $100 \mu \mathrm{g} / \mathrm{ml}$ streptomycin sulphate (Euroclone, Celbio) and $2 \mathrm{mmol} / \mathrm{l}$ glutamine (Mediatech, Cellgro, VA, USA).

In vitro islet characterisation In vitro characterisation of islets was performed on islet material processed within $72 \mathrm{~h}$ after isolation and all the quality tests were performed on samples collected before the transplant.

Morphology, purity and mass of isolated endocrine tissue were assessed on 100- $\mu$ l aliquots of the final prepara- tion previously dispersed in $250 \mathrm{ml}$. Islets were stained with diphenyl-thiocarbazone, counted at the microscope and the number expressed as absolute number (NA) and equivalent number (NE; the absolute number corrected for coefficients based on islet volume, [11]). According to their morphology, islets were divided into two categories: (1) roundshaped, when they maintained their morphology and a large portion of the peripheral capsule; (2) fragmented, when they showed architectural disorganisation with irregular borders and free chains of cells protruding from the periphery. Islet preparations were classified on the basis of the predominant morphology ( $>50 \%$ of all islets analysed).

Two aliquots of 1,000 NE were sonicated in distilled water for the assessment of insulin (MEIA insulin, IMX System; Abbott Laboratories, Abbott Park, IL, USA), protein (Pierce, Celbio, Milan, Italy) and amylase (AMY-P; Roche) content. Insulin content was normalised to NE, amylase and protein content.

To assess insulin responsiveness to glucose after exposure to glucose, islet cells were stimulated for $20 \mathrm{~min}$ with $16.7 \mathrm{mmol} / 1$ glucose after $20 \mathrm{~min}$ of equilibration with 3.3 $\mathrm{mmol} / \mathrm{l}$, and data expressed as a secretion index, calculated as the ratio between stimulated and basal insulin values [12].

Two probes for islet viability were used: propidium iodide and Fura-2-AM (Sigma-Aldrich). The $\mathrm{Ca}^{2+}$ indicator served as a viability probe, since it measures both the enzymatic activity that is required to activate their fluorescence and the cell-membrane integrity that is required for intracellular retention of its fluorescent product [13-15]. A minimum of 20 different islets were examined per preparation. Fura-2 and propidium iodide images were recorded at three different islet levels in order to have a value representative of the whole islet. The number of positive islet cells to propidium iodide was expressed as areas positive to the dye/total area; the images were analysed by the Image Pro Plus software (Media Cybernetics, Silver Spring, MD, USA). After propidium iodide and Fura- 2 staining, the islets were further stained with diphenyl-thiocarbazone in order to assess the presence of insulin in the analysed sample.

Islet transplantation Transplantation was performed between 2 and $72 \mathrm{~h}$ after isolation. Islet quality tests were performed on material processed shortly before transplant. Preparations were considered adequate for transplantation according to the following criteria: (1) NE $(>5,000$ per kg bodyweight); (2) purity $>20 \%$ (dithizone-staining determination of islet/total mass); and (3) islet sterility [16]. Purification was defined to be $20 \%$ or greater, because in our experience this limit maintains the tissue volume for transplant to less than $10 \mathrm{ml}$.

The islet preparation was suspended in $100 \mathrm{ml}$ of Hanks' salt solution (Hanks Clinical Grade; SALF, Bergamo, Italy) or in CMRL (Transplant Medium, Mediatech, VA, USA) containing 1,000-2,000 U of heparin and $2 \%$ human serum albumin, and was transplanted by percutaneous transhepatic injection (under local anaesthesia).

A total of 106 islet preparations were transplanted into 74 HLA-mismatched recipients affected by type 1 diabetes mellitus (median duration of diabetes, 32 years; range 12 
48). The percentage of transplanted preparation was $24.7 \%$ of all pancreas processed, ranging during a 6-month period from 0 to $65 \%$.

Different immunosuppression regimens were adopted. In 46 patients who received islets simultaneously or after kidney transplant, the therapy was based on: anti-lymphocyte globulin (125 mg/day for 10 days; Thymoglobulin, Merieux, Lyon, France); cyclosporine (7.5 $\mathrm{mg} \mathrm{kg}^{-1} \mathrm{day}^{-1}$ ); mycophenolate mofetil ( $2 \mathrm{~g}$ /day); and methylprednisone (500 mg immediately before surgery, $0.25 \mathrm{mg} \mathrm{kg}^{-1} \mathrm{day}^{-1}$ for 2 months after surgery, then lowered to $5 \mathrm{mg} /$ day). In 12 patients with brittle diabetes the therapy was the Edmonton protocol, including daclizumab $(1 \mathrm{mg} / \mathrm{kg}$ every 14 days, for a total of five doses; Zenapax, Roche), sirolimus ( $0.1 \mathrm{mg}$ $\mathrm{kg}^{-1}$ day ${ }^{-1}$, Rapamune, Wyeth-Ayerst) and low dosage tacrolimus (serum level $=3-6 \mathrm{ng} / \mathrm{ml}$, Prograf, Fujisawa) [1]. The other 16 patients were transplanted in other hospitals or treated with an experimental therapy based on mycophenolate mofetil and vitamin D3. Of these patients, 24 received a single islet preparation with a follow-up of at least 1 month (14 receiving islet after kidney transplantation, and ten receiving islet transplantation alone) and were used for correlations between islet isolation parameters and transplantation outcome.

Recipients gave informed consent and our investigations were approved by the responsible ethics committee (institutional review board). Studies were carried out in accordance with the Declaration of Helsinki as revised in 2000 (http://www.wma.net/e/policy/b3.htm).

Statistical analyses Outcomes in the 437 pancreases that were examined were (1) the total number of islets expressed as NE; and (2) an islet yield of $>250,000 \mathrm{NE}$ and $>20 \%$ purity. Variables analysed for association with these outcomes were:

1. Donor characteristics: sex, age, BMI, cause of death (non-traumatic or traumatic), intensive care unit days, blood glucose and amylase (level before organ removal), dopamine and noradrenalin dose

2. Pancreas: organ condition (good or bad), presence of fatty infiltrates (yes or no), weight

3. Organ procurement: procurement team (local or external), preservation solution (Celsior or UW), duration of cold storage

4. Digestion characteristics: type of enzyme (collagenase type $\mathrm{P}$ or liberase), batch of enzyme, collagenase activity/mg of enzyme, collagenase activity/solution volume, collagenase activity $\times$ total $\mathrm{mg}$ of used enzyme in an isolation (total collagenase activity), collagenase activity/mg adjusted for $\mathrm{mg}$ of enzyme used in an isolation (adjusted collagenase activity/mg), collagenase activity/weight of pancreas, neutral protease activity/ $\mathrm{mg}$ of enzyme, neutral protease activity/solution volume, the ratio between the activity of collagenase and neutral protease, clostripain and trypsin activity/mg of enzyme, digestion time, proteins used for dilution (fetal calf serum or human albumin)
5. Purification procedure: discontinuous or continuous density gradient.

A separate analysis was performed for transplant outcome in transplanted islet preparations. For this analysis only transplants where single first islet preparations were transplanted into a patient with C-peptide levels $<0.05 \mathrm{ng} / 1$ and where there was a minimum of 1 month follow-up before further islets were transplanted were considered $(n=24)$. Outcomes were defined as C-peptide values and the reduction in insulin requirement (the decreased dosage of insulin unit administered to keep the recipient normoglycaemic) 1 month after transplant.

Variables did not show a Gaussian distribution, and a non-parametric analysis was performed. Comparisons between groups were performed by Mann-Whitney $U$ test or Kruskal-Wallis test, where one of the variables or the outcome was a nominal value, and the Chi square test when both the variable and outcome were nominal values. Where both the variable and outcome were ordinal values, correlations were performed using the Spearman rank correlation test and expressed as Spearman's correlation coefficient. All comparisons are two-tailed. A $p$ value of less than 0.01 was considered to be statistically significant. Multiple regression analysis was performed with rank transformed data of the variables with a $p$ value of less than 0.05 , two-tailed in the univariate analysis, in order to take into account the effects of confounding variables.

\section{Results}

Islet yield and purity The number of isolated islets varied greatly between different isolations (median NA, 195,000; interquartile range [IQR], 105,000-297,000; median NE, 189,250; IQR 100,000-320,250). By univariate analysis (Table 1), NE was significantly associated with donor age $(r=0.16 ; p=0.0009)$, BMI $(r=0.19 ; p=0.0004)$, pancreas condition (median NE good 199,000; IQR 106,000-327,000; median NE bad 126,000; IQR 59,000-230,000; $p=0.0031$ ) and weight $(r=0.15 ; p=0.0056)$, total collagenase activity $(r=0.22 ; p=0.0001)$, adjusted collagenase activity $/ \mathrm{mg}(r=$ $0.18 ; p=0.0002)$, collagenase activity/solution volume ( $r=$ $0.18 ; p=0.0002)$ and neutral protease activity/solution volume $(r=0.14 ; p=0.0029)$. Multivariate analysis was performed among significant variables grouped by category. A statistically significant contribution to the variability of islet yield in a multivariate analysis performed on donor variables was found for donor BMI ( $p=0.0008)$. In a multivariate analysis performed on pancreas variables a contribution was found for pancreas weight ( $p=0.0064)$, and for a multivariate analysis performed on digestion variables we found a contribution for digestion time $(p=0.0048)$ and total collagenase activity $(p=0.0001)$.

Isolations were also classified as successful $(>250,000$ $\mathrm{NE}$ and $\geq 20 \%$ purity) or unsuccessful. Of the 437 pancreases analysed, $36 \%$ were classified as successful, another $3 \%$ yielded $>250,000 \mathrm{NE}$ with $<20 \%$ purity, $49 \%$ 
Table 1 Univariate analyses between isolation variables and islet yield and successful isolation

\begin{tabular}{|c|c|c|c|c|}
\hline Isolation variables & Individuals & Characteristics & Islet yield ${ }^{\mathrm{a}} p$ & Successful isolation $^{\mathrm{b}} p$ \\
\hline \multicolumn{5}{|l|}{ Donor } \\
\hline $\operatorname{Sex}^{\mathrm{c}}$ & 431 & 261 males; 170 females & 0.0981 & 0.0708 \\
\hline Age (years) & 430 & $42(30-52)$ & $0.0009^{\mathrm{d}}$ & 0.0204 \\
\hline BMI $\left(\mathrm{kg} / \mathrm{m}^{2}\right)$ & 338 & $24(22-26)$ & $0.0004^{\mathrm{d}}$ & $0.0074^{\mathrm{d}}$ \\
\hline Cause of death ${ }^{c}$ & 398 & 140 traumatic; 258 non-traumatic & 0.1195 & 0.8957 \\
\hline Intensive care unit days & 272 & $2(1-4)$ & 0.4797 & 0.8652 \\
\hline Blood glucose (mmol/l) & 205 & $7.8(6.1-9.9)$ & 0.8916 & 0.8717 \\
\hline Amylase level (U/l) & 191 & $90(51-195)$ & 0.4942 & 0.4859 \\
\hline Dopamine dose $\left(\mathrm{kg}^{-1} \min ^{-1}\right)$ & 185 & $6(3-8) \mu U$ & 0.6344 & 0.7190 \\
\hline Noradrenalin dose $\left(\mu \mathrm{g} \mathrm{kg}^{-1} \mathrm{~min}^{-1}\right)$ & 155 & $0.000(0.000-0.001)$ & 0.2252 & 0.4017 \\
\hline \multicolumn{5}{|l|}{ Pancreas } \\
\hline Organ condition $^{c}$ & 392 & 321 good; 71 bad & $0.0031^{\mathrm{d}}$ & $0.0024^{\mathrm{d}}$ \\
\hline Presence of fatty infiltrates ${ }^{c}$ & 165 & 76 yes; 89 no & 0.0192 & 0.0155 \\
\hline Weight $(g)$ & 345 & $80(70-103)$ & $0.0056^{\mathrm{d}}$ & $0.0050^{\mathrm{d}}$ \\
\hline Procurement team ${ }^{c}$ & 423 & 211 local; 212 external & 0.0128 & 0.0964 \\
\hline Preservation solution $^{\mathrm{c}}$ & 266 & 47 Celsior; 219 Belzer & 0.4372 & 0.3851 \\
\hline Duration of cold storage $(\mathrm{h})$ & 335 & $6(4-8)$ & 0.1358 & 0.4239 \\
\hline \multicolumn{5}{|l|}{ Digestion } \\
\hline Type of enzyme & 432 & 260 type P; 172 Liberase & 0.3560 & 0.6366 \\
\hline Batches $^{c}$ & 247 & 11 & 0.0280 & \\
\hline Collagenase activity/mg of enzyme (U/mg) & 432 & $2.7(2.3-4.2)$ & 0.7356 & 0.9865 \\
\hline Collagenase activity/ solution volume $(\mathrm{U} / \mathrm{ml})$ & 431 & $6.8(5.4-7.3)$ & $0.0002^{\mathrm{d}}$ & 0.1716 \\
\hline Total collagenase activity $(\mathrm{U})$ & 431 & $2,160(1,930-2,880)$ & $0.0001^{\mathrm{d}}$ & 0.0331 \\
\hline Adjusted collagenase activity/mg (U/mg) & 431 & $4.3(3.9-5.8)$ & $0.0002^{\mathrm{d}}$ & 0.0954 \\
\hline Collagenase activity/weight of pancreas (U/mg) & 341 & $25(19.2-34)$ & 0.3257 & 0.5982 \\
\hline Neutral protease activity/mg of enzyme (U/mg) & 431 & $138(80-157)$ & 0.4820 & 0.9074 \\
\hline Neutral protease activity/solution volume $(\mathrm{U} / \mathrm{ml})$ & 431 & $244(212-376)$ & $0.0029^{\mathrm{d}}$ & 0.1251 \\
\hline Collagenase/neutral protease activity (mU/U) & 431 & $25.5(20.3-28.5)$ & 0.8846 & 0.8354 \\
\hline Clostripain/mg of enzyme (U/mg) & 432 & $3.1(0-8.1)$ & 0.7241 & 0.9343 \\
\hline Trypsin activity/mg of enzyme (U/mg) & 431 & $0.1(0-1.1)$ & 0.9094 & 0.9889 \\
\hline Digestion time (min) & 412 & $25(19-34)$ & 0.0153 & 0.0379 \\
\hline Proteins for dilution $^{\mathrm{c}}$ & 422 & 338 FCS; 84 human albumin & 0.1370 & 0.3425 \\
\hline \multicolumn{5}{|l|}{ Purification } \\
\hline Method $^{\mathrm{c}}$ & 411 & 204 discontinuous; 207 continuous & 0.1202 & 0.6203 \\
\hline
\end{tabular}

Data are expressed as median values with interquartile ranges in parentheses

${ }^{\mathrm{a}}$ Islet yield is expressed as NE

${ }^{\mathrm{b}}$ Successful isolations were those that contained at least 250,000 islet equivalents and were at least $20 \%$ pure

${ }^{c}$ Nominal variables analysed by Mann-Whitney $U$ test, Kruskal-Wallis test or Chi square test (successful), as appropriate. Other variables were analysed by Spearman rank correlation coefficient or Mann-Whitney $U$ test (successful) $\mathrm{d}_{p}<0.01$

yielded $\leq 250,000 \mathrm{NE}$ with $\geq 20 \%$ purity, and $12 \%$ yielded $\leq 250,000 \mathrm{NE}$ with $<20 \%$ purity. By univariate analysis (Table 1), successful isolation was associated with BMI (for successful isolations median $25 \mathrm{~kg} / \mathrm{m}^{2}$, IQR $23-28 \mathrm{~kg} / \mathrm{m}^{2}$; for failed isolations $24 \mathrm{~kg} / \mathrm{m}^{2}$, IQR $22-26 \mathrm{~kg} / \mathrm{m}^{2}, p=$ 0.0074 ), pancreas weight (for successful isolations median $100 \mathrm{~g}$, IQR $80-114 \mathrm{~g}$; for failed isolations $90 \mathrm{~g}$, IQR 75$100 \mathrm{~g}, p=0.0050)$ and pancreas condition $(91 \%$ good condition for successful isolations; $77 \%$ for failed isolations, $p=0.0024)$. A statistically significant contribution to the likelihood of a successful isolation in a multivariate analysis performed on pancreas variables was found for pancreas weight ( $p=0.0010$ ) and in a multivariate analysis performed on digestion variables a contribution was found for total collagenase activity ( $p=0.0037)$. No donor variables reached a $p$ value of lower than 0.01 at the multivariate analysis.

In vivo islet function after transplantation Twenty-four preparations were transplanted as single donor preparations in patients with type 1 diabetes. Fourteen patients received islets after kidney transplantation and ten patients islets alone for brittle diabetes. Their median pre-transplant insulin requirement was $40 \mathrm{U}$ (IQR 36-59 U). One month after transplantation the median insulin requirement was reduced to $20 \mathrm{U}$ (IQR 8-32 U) and 3 months after transplantation it fell to $18 \mathrm{U}$ (IQR 7-31) (Fig. 1). The median C-peptide value at 1 month follow-up was $1.3 \mathrm{ng} / \mathrm{ml}$ (IQR $1.0-2.3 \mathrm{ng} / \mathrm{ml}$ ) and at 3 months follow-up $1.5 \mathrm{ng} / \mathrm{ml}$ (IQR 


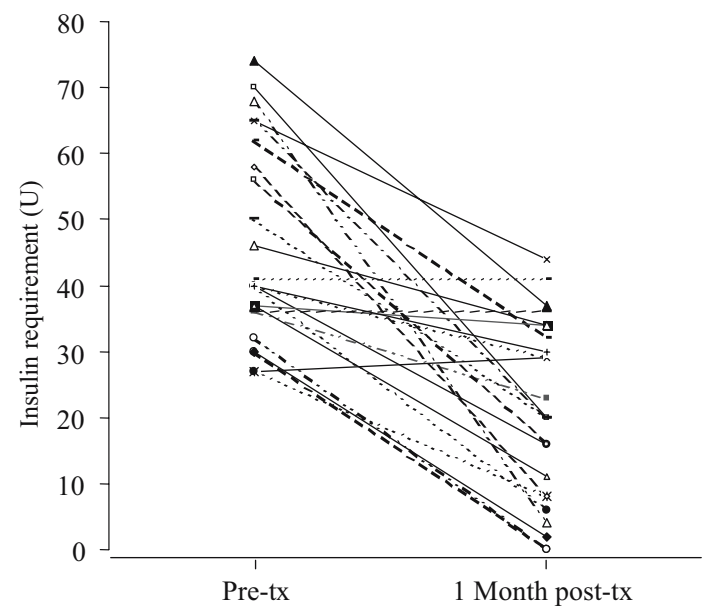

Fig. 1 Variation of insulin requirement during the first month of follow-up in the 24 recipients who received single islet infusion. $t x$, transplant

$0.7-2.3 \mathrm{ng} / \mathrm{ml})$. Six patients reached insulin independence at 1.5 month follow-up (median value, IQR 0.4-2.7 months).

Fasting C-peptide values and the reduction in insulin requirement at 1 month follow-up were used as outcome measures. These were correlated with each other $(r=0.55$; $p=0.0054)$. The larger reduction in insulin requirement was significantly associated with higher isolation index and a higher pre-transplant insulin requirement (Table 2). Multivariate analysis including all variables with $p<0.05$ identified morphological aspects of islets as significantly contributing to the variation of the insulin reduction at 1 month ( $p=0.0052$ ), also after adjustment of the analysis for the pre-transplant insulin requirement $\left(p=0.0010, r^{2}=32 \%\right)$.

Increased 1 month $\mathrm{C}$-peptide values were significantly associated with higher NE, higher islet purity, higher isolation index, preparations with predominantly round-shaped islets, higher NE per kilogram bodyweight, and the islet after kidney transplant protocol (Table 2). These variables were also significant when $\mathrm{C}$-peptide concentrations were adjusted for glycaemia (data not shown). Multivariate analyses identified only purification as significantly contributing to the variation of the 1 month C-peptide concentration $(p=0.0071)$.

There were no significant differences between islet isolation parameters in the patients who achieved insulin independence within 6 months follow-up $(n=6)$ and those who did not $(n=18)$, with the exception of islet morphology (6/6 good-aspect islets in recipient insulin-independent versus $9 / 18$ in recipient insulin-dependent, $p=0.0001$ ).

Since islet morphology represented an important parameter for islet function, an analysis to determine which variables were associated with the morphological aspects of the islets was performed. Morphological aspects of the islets were strictly correlated with each other $(p=0.0001)$. In particular, the isolation index was highest in preparations containing predominantly round-shaped islets (median index 1.05; IQR 0.82-1.3) and lower in preparations containing predominantly fragmented islets (median 0.8 ; IQR

Table 2 Univariate analyses between islet quality, transplant parameters and graft function 1 month post-transplant

\begin{tabular}{|c|c|c|c|c|c|c|c|}
\hline \multirow[t]{2}{*}{ Variables } & \multirow[t]{2}{*}{ Median (IQR) } & \multicolumn{3}{|c|}{ Reduced insulin requirement } & \multicolumn{3}{|c|}{ C-peptide } \\
\hline & & $r$ & Median (IQR) & $p$ & $r$ & Median (IQR) & $p$ \\
\hline \multicolumn{8}{|l|}{ Islet quality parameter } \\
\hline NA $10^{3}(n=24)$ & $335(284-458)$ & 0.08 & & 0.7102 & 0.03 & & 0.8893 \\
\hline NE $10^{3}(n=24)$ & $347(270-434)$ & 0.36 & & 0.0846 & 0.61 & & $0.0016^{\mathrm{a}}$ \\
\hline Purity $(n=24)$ & $50(30-70)$ & 0.20 & & 0.3488 & 0.55 & & $0.0080^{\mathrm{a}}$ \\
\hline Isolation index $(n=24)$ & $0.97(0.79-1.12)$ & 0.54 & & $0.0065^{\mathrm{a}}$ & 0.56 & & $0.0044^{\mathrm{a}}$ \\
\hline Morphological aspect $(n=24)$ & & & & 0.0155 & & & $0.0095^{\mathrm{a}}$ \\
\hline Round shaped (\%) & 62.5 & & $32(25-44)$ & & & $1.4(1.2-2.6)$ & \\
\hline Fragmented $(\%)$ & 37.5 & & $12(0-26)$ & & & $0.8(0.3-1.2)$ & \\
\hline $\mathrm{Ca}^{++}$concentration $(340 / 380)(n=14)$ & $385(310-430)$ & -0.29 & & 0.3145 & -0.11 & & 0.7081 \\
\hline Propidium iodide $(\%)(n=11)$ & $14(10-20)$ & 0.25 & & 0.4584 & 0.18 & & 0.5964 \\
\hline Insulin secretion (SI) $(n=12)$ & $2.0(1.7-2.6)$ & 0.10 & & 0.7572 & 0.60 & & 0.0392 \\
\hline Insulin/amylase ratio $(\mu \mathrm{U} / \mathrm{mU})(n=12)$ & $134(16-328)$ & 0.46 & & 0.1324 & 0.18 & & 0.5726 \\
\hline Insulin/protein ratio $(\mathrm{pm} / \mathrm{ng})(n=10)$ & $3.0(1.0-9.5)$ & 0.56 & & 0.0923 & 0.02 & & 0.9563 \\
\hline Insulin/NE ratio $(\mu \mathrm{U} / \mathrm{NE})(n=12)$ & $186(77-335)$ & -0.06 & & 0.8531 & -0.40 & & 0.1976 \\
\hline \multicolumn{8}{|l|}{ Transplant parameters } \\
\hline Pre-transplant insulin $\mathrm{U}(n=24)$ & $40(36-59)$ & 0.59 & & $0.0024^{\mathrm{a}}$ & 0.44 & & 0.0314 \\
\hline NE/kg bodyweight $(n=24)$ & $5,845(4,484-7,561)$ & 0.46 & & 0.0237 & 0.52 & & $0.0092^{\mathrm{a}}$ \\
\hline Transplant protocol $(n=24)$ & & & & 0.4720 & & & $0.0071^{\mathrm{a}}$ \\
\hline Islet alone $(\%)$ & 42 & & $27(11-30)$ & & & $1.0(0.3-1.2)$ & \\
\hline Islet after kidney (\%) & 58 & & $27(10-46)$ & & & $2.1(1.2-2.9)$ & \\
\hline Time of pre-transplant culture $(n=24)$ & $24(4-24)$ & -0.01 & & 0.9630 & 0.33 & & 0.1153 \\
\hline
\end{tabular}

${ }^{\mathrm{a}} p<0.01$ 
0.7-1.0). By univariate analysis, islet morphology was associated with purification procedure (discontinuous method: $68 \%$ round-shaped, $32 \%$ fragmented; continuous method: $42 \%$ round-shaped, $58 \%$ fragmented; $p=0.0060$ ). Similarly, the isolation index was greater in preparations purified by the discontinuous method than in preparations purified by the continuous method $(p=0.0002)$.

\section{Discussion}

Human islets isolated from dead donors are the only cell source that currently can be used for cell-based therapies to cure type 1 diabetes. Isolating high numbers of pure intact islets is therefore of paramount importance. By examining donor, digestion, purification, and islet characteristics in a large series of pancreas isolations, we found that large pancreases obtained from obese donors and quickly digested with a high quantity of high-activity collagenase were associated with a high yield of islets suitable for transplantation. The ability of islet preparations to reduce insulin requirement in the patient was best predicted by islet morphology under the microscope.

These data have been collected over a period of 14 years, allowing analysis of data from a large number of human pancreases. The large number of variables examined represents a strength and a weakness of the study. On the one hand, it highlights the large number of variables that can influence the outcome of islet isolation; on the other hand, some of the associations found in univariate analyses may be secondary to confounder variables or statistical error. The multivariate analyses that were performed on the data obtained did distinguish those associations that most strongly influenced outcome, but are likely to have low statistical power with respect to identifying variables with modest independent effects, and we therefore cannot exclude that some of the non-significant variables in the multivariate analysis do actually contribute to islet yield, purity, or function. Finally, despite the continuity of procedures, many of the variables examined have a significant number of missing data, and we cannot exclude that some of the associations may be biased by these cases.

Few analyses of islet isolation have been reported [4-8]. Consistent with the multivariate analysis of our data, most of these reports also found that high numbers of islets were best obtained from donors with high BMI $[4,5,7,8,17$, 18]. This condition is often considered to be a marker of insulin resistance and of high metabolic demand, both of which represent a stimulus for islet neogenesis (beta cell adaptation) that increases the overall native beta cell mass [19]. In addition the presence of fat tissue during digestion or of a thick capsule around the islets from old donors further improved isolation outcome in the analysis from the Giessen isolation unit [17]. These factors probably act by limiting the exposure of free islets to collagenase in solution, thus preserving islet integrity and survival [17]. We did not find a significant influence of duration of cold ischaemia time on isolation yield, probably because most pancreases were processed within $12 \mathrm{~h}$.
A novel aspect of our study was the analysis designed to find collagenase parameters associated with high isolated islet yield and quality. Pancreas digestion, and in particular the choice of collagenase, are critical for isolation success $[7,20]$. The use of batches with high collagenase activity per total enzyme was an important determinant for successful isolation. Collagenase should be used in conditions that render it highly active. This can be achieved by selecting only enzyme blends with the highest collagenase activity, or may be achieved by increasing the amount of enzyme used or the temperature at which digestion is performed. Over-digestion is undesirable, since it produces many fragmented islets. This appears to result from a delayed interruption of digestion and a relatively long exposure of free islets to collagenase, such as when a long digestion time is required for isolation. It is clear, however, that many aspects of the collagenase reagent are critical in the isolation procedure and that further studies are required to better characterise enzyme blends and their composition.

Transplantation of a sufficient and purified islet mass was demonstrated to be an important pre-requisite for successful transplantation [2]. Other factors such as the inflammatory reaction during engraftment [21], the metabolic condition [22] or the allo- and auto-response of recipients $[23,24]$ have also been shown to influence in vivo function of transplanted islets. Islet quality may, therefore, represent another prerequisite for successful transplantation. Various measures of vitality, morphological assessments, and in vitro secretion have been proposed to assess islet quality [1]. These and other parameters were analysed with respect to in vivo function in 24 single islet preparations. Islet morphology appeared one of the most important parameters correlated with 1 month graft function. The definition of islet morphology is a subjective parameter that is likely to be difficult to standardise. A more suitable parameter of islet integrity might be the isolation index. This can be easily calculated from the NE and NA counts. NE is usually calculated by normalising the absolute number of islets (divided into different classes according to their diameter) per relative conversion factor into islets of $150-\mu \mathrm{m}$ diameter [1]. If NE is lower than NA (isolation index $<1$ ), a preparation has a prevalence of islets smaller than $150-\mu \mathrm{m}$ diameter, and this might be a sign of islet over-digestion and of derangement in their morphological integrity. The isolation index correlated strictly with NE and with islet morphology, and may therefore be a marker not only of islet volume but also of islet quality. Other morphometric parameters such as beta cell content or insulin content may also provide useful measures of islet quality.

This study provides a guide for donor, digestion, purification, and islet characteristics that may improve the efficiency and efficacy of islet transplantation. However, it should be remembered that even when optimal donors and enzymes are used, islet yield and quality are likely to be highly variable between preparations. The development of novel methods of isolation should therefore be encouraged. 
Acknowledgements This work was supported by grants from the Juvenile Diabetes Research Foundation (5-2001-172, 1-2000-780, JT-01) and from Telethon Italy (JT-01). We are grateful to the Nord Italia Transplant Organization that coordinates organ collection in the North of Italy and to all the surgical team of other North Italia Hospitals that, under the coordination of Nord Italia Transplant Organization, continue to collect pancreases for our Institute. We are also grateful to the "Associazione Cellule staminali, oltre il diabete" for continuously supporting our studies.

\section{References}

1. Shapiro AMJ, Lakey JRT, Ryan EA et al (2000) Islet transplantation in seven patients with type 1 diabetes mellitus using a glucocorticoid-free immunosuppressive regimen. N Engl J Med 343:230-238

2. Ryan EA, Lakey JRT, Rajotte RV et al (2001) Clinical outcomes and insulin secretion after islet transplantation with the Edmonton protocol. Diabetes 50:710-719

3. Ricordi C, Lakey JR, Hering BJ (2001) Challenges toward standardization of islet isolation technology. Transplant Proc 33:1709

4. Lakey JR, Warnock GL, Rajotte RV et al (1996) Variables in organ donors that affect the recovery of human islets of Langerhans. Transplantation 61:1047-1053

5. Brandhorst D, Brandhorst H, Hering BJ, Federlin K, Bretzel RG (1995) Islet isolation from the pancreas of large mammals and humans: 10 years of experience. Exp Clin Endocrinol Diabetes 103 (Suppl 1):3-14

6. Fiedor P, Goodman ER, Sung RS, Czerwinski J, Rowinski W, Hardy MA (1996) The effect of clinical and biochemical donor parameters on pancreatic islet isolation yield from cadaveric organ donors. Ann Transplant 1:59-62

7. Benhamou PY, Watt PC, Mullen Y et al (1994) Human islet isolation in 104 consecutive cases. Factors affecting isolation success. Transplantation 57:1804-1810

8. Zeng Y, Torre MA, Karrison T, Thistlethwaite JR (1994) The correlation between donor characteristics and the success of human islet isolation. Transplantation 57:954-958

9. Ricordi C, Lacy PE, Finke EH, Olack BJ, Scharp DW (1988) Automated method for isolation of human pancreatic islets. Diabetes 37:413-420

10. Vargas F, Vives-Pi M, Somoza N et al (1996) Advantages of using a cell separator and metrizamide gradients for human islet purification. Transplantation 61:1562-1566
11. Ricordi C, Hering B, London N, Rajotte R, Gray D, Sutherland D, Socci C, Alejandro R, Carrol PB, Bretzel R, Scharp DW (1992) Islet isolation assessment. In: Ricordi C (ed) Pancreatic islet cell transplantation. R.G. Landes, Austin, USA, pp 132142

12. Bertuzzi F, Garancini P, Socci C et al (1999) Lessons from invitro perifusion of pancreatic islets isolated from 80 human pancreas. Cell Transplant 8:709-712

13. Dziki AJ, Batzri S, Harmon JW, Molloy M (1995) Cellular hypercalcemia is an early event in deoxycholate injury of rabbit gastric mucosal cells. Am J Physiol 269:G287-G296

14. Ferger D, Krieglstein J (1996) Determination of intracellular $\mathrm{Ca} 2+$ concentration can be a useful tool to predict neuronal damage and neuroprotective properties of drug. Brain Res 732: 87-94

15. Bertuzzi F, Davalli AM, Nano R et al (1999) Mechanisms of coordination of $\mathrm{Ca} 2+$ signals in pancreatic islet cells in response to glucose stimulation. Diabetes 48:1971-1978

16. Bertuzzi F, Grohovaz F, Maffi P et al (2002) Successful transplantation of human islets in recipients bearing a kidney graft. Diabetologia 45:77-84

17. Mahler R, Franke FE, Hering BJ et al (1999) Evidence for a significant correlation of donor pancreas morphology and the yield of isolated purified human islets. J Mol Med 77:87-89

18. Brandhorst H, Brandhorst D, Hering BJ, Federlin K, Bretzel RG (1995) Body mass index of pancreatic donors: a decisive factor for human islet isolation. Exp Clin Endocrinol Diabetes 103 (Suppl 2):23-26

19. Liu YQ, Jetton TL, Leahy JL (2002) Beta-cell adaptation to insulin resistance. Increased pyruvate carboxylase and malatepyruvate shuttle activity in islets of nondiabetic Zucker fatty rats. J Biol Chem 277:39163-39168

20. Linetsky E, Bottino R, Lehmann R, Alejandro R, Inverardi L, Ricordi C (1997) Improved human islet isolation using a new enzyme blend, Liberase. Diabetes 46:1120-1123

21. Piemonti L, Leone BE, Nano R et al (2002) Human pancreatic islets produce and secrete MCP-1: relevance in human islet transplantation. Diabetes 51:55-65

22. Luzi L, Hering BJ, Socci C et al (1995) Metabolic effects of successful intraportal islet transplantation in IDDM. J Clin Invest 97:2611-2618

23. Bosi E, Braghi S, Maffi P et al (2001) Autoantibody response to islet transplantation in type 1 diabetes. Diabetes 50:2464-2471

24. Roep BO, Stobbe I, Duinkerken G et al (1999) Auto- and alloimmune reactivity to human islet allografts transplanted into type 1 diabetic patients. Diabetes 48:484-490 